Cooked fruits often disagree because of the fermentation of the added sugar, which in the presence of the fruit acids, takes place readily, or forms organic acids which interfere with digestion!.

Fish may be made to take the place of meat to a great degree; the harder and finer the texture of the fish, and the darker and more oily it be, the harder it is to digest, but if digestion be good, nearly all kinds can be eaten, especially if properly cooked. The rule should be, to never fry them, but bake, broil, or best of all, boil them. With very weak digestion, flounders boiled ten minutes in a little salted water are well borne. Animal food is denied by many, and advocated by as good authority, but I am inclined to the opinion that it is quite generally conceded to be harmful and certainly unnecessary; except in a few cases where the light-colored meats may be used to "break the monotony" of diet, they are best let alone.

Fats, starches and sugars, when properly cooked and digested, do not contribute to the formation of uric acid, and their free consumption acts to restrict the amount of proteid or nitrogenous food. Good fresh butter, oils in salads, bacon, etc., lessen by their heat production the retrograde metamorphosis of the body albumins and satisfy appetite. Most of the starchy foods may be eaten with impunity, if properly cooked. Bread should be stale or toasted, and the German toast or "zwieback" should take the place of crackers.

I have not attempted to cover the ground of medicinal treatment; and, with proper diet, but little will be required in the main, except during the "explosive" attacks.

In closing, let me say that with our diet, we should encourage employment and outdoor pleasures; and pleasant exercise, either active or passive, for those confined to the house by infirmity or otherwise.

Stimulate the depressed and melancholic conditions by cheerful companionship, but teach our patient that he who makes of his stomach a god is a fool, and that "good cheer" with brandy and soda, makes urate of soda and gout.

762 East McMillan Street.

\section{A CYST OF THE PANCREAS: OPERATION: RECOVERY.*}

BY JAMES B. EAGLESON, M.D. SEATTLE, WASH.

Mrs. J. K., 34 years old and a native of Norway, was referred to me by Dr. Gibson of Seattle. Her family history was negative and she did not remember having received an injury of any kind in the abdomen. She has two children, aged 16 and 5 years, and has had two abortions, the last two years ago. Her general health had always been quite good, until 1896, when she began to have some indigestion and distress in the stomach, and this gradually increased.

In Mav, 189\%, she had a sudden attack of severe pain in the left side, in the region of the kidney, accompanied by serere nausea and vomiting. The attack was thought by some to be acute pleurisy, but no definite diagnosis was determined on. It lasted about five weeks. A second attack occurred in the latter part of July, diagnosed as some disease of the uterus and ovaries, and an immediate operation was advised. She was sent to the hospital in Spokane, where she was then living, and had the uterus curetted and a laceration

* I'resented to the Section on Surgery and Anatomy, at the Fiftieth Annual Meeting of the American Medical Association. beld at Columbus. Ohio, June 6-9, 1999. of the cervix repaired. About ten days later a double oöphorectomy was performed. She left the hospital in four weeks after this, somewhat improved, but in about two weeks after going home the attacks of pain returned, more severe than before. During the following winter they returned at frequent intervals and were occasionally accompanied by a slight cystitis. In February, 1898, her condition was diagnosed as a stone in the left kidney, and an operation for its removal was advised. About one month later she noticed a tumor in the left side, when lying in a certain position. The appetite remained poor and she continued to lose flesh, but during the summer after coming to Seattle the attacks were not so frequent and were less severe. However, as the cold weather came again the attacks were more pronounced, and about the middle of November her attending physician had her removed to Providence hospital and called me in consultation.

I found her very much emaciated and the skin presented a wrinkled appearance and had a decided bronze tinge. She felt a repugnance toward eating, and the food taken was frequently rejected. Her temperature ranged from 99 to 101 . Her sleep was very restless and broken. There was a movable tumor in the upper part of the left lumbar region, which dropped forward, downward and toward the median line when in the erect position, coming as low as the umbilicus. It was somewhat tender on palpation and seemed to be a solid tumor. The tenderness was much more marked during the attacks of pain, which would frequently radiate downward in the direction of the ureter, and would be accompanied by an irritation of the bladder. The urine collected from the kidneys, by the Harris instrument, showed no apparent difference on analysis. That voided gave a deposit of a few pus cells and bladder epithelium from the cystitis. The quantity of the urine passed was somewhat below normal, but was occasionally considerably increased immediately after the subsidence of the acute pain. The kidney could not be outlined in its normal position. No definite diagnosis was arrived at, but the tumor was thought to be an enlarged floating kidney, and an exploratory operation was decided on with a view to making a thorough examination of the kidney, and if it was found to be healthy, to fix it to the lumbar muscles.

I operated on November 28 , and was assisted by Drs. W. C. Gibson, C. B. Ford and H. D. Kline. The usual lumbar incision was made for exploring the kidney, which was found to be apparently healthy and in its normal position. Through this incision the tumor could be located as extending from a fixed point just above the kidney downward and forward into the abdominal cavity, and was pear-shaped. As soon as we discovered that we had to deal with an intraperitoneal tumor, the lumbar wound was closed up by buried catgut and cutaneous silkworm gut sutures.

The patient was then changed to the dorsal position on the table and an incision was made over the most prominent part of the tumor, which was at the outer border of the left rectus muscle. The lower end of the tumor, covered by omentum, was brought into the wound. It was oval and about $12 \mathrm{~cm}$. in diameter. The left end of the transverse colon passed over its center, and the stomach was drawn down over the upper end. It was smooth, but very dense and hard, resembling a solid tumor on palpation. The first thought was that it must be a malignant growth, and from the apparent depth of its attachments, the advisability of at- 
tempting its removal was questioned. An opening was torn through the gastrocolic omentum and the tumor wall exposed; it had a dark bluish color resembling a cyst.

It was now diagnosed as a pancreatic cyst and I decided on immediate incision and drainage. The edges of the omentum, which was firmly adherent to the cyst wall, were stitched to the peritoneum of the abdominal wound in order to prevent leakage into the abdominal cavity. An incision 1 inch long was now made into the cyst and its contents drained out by turning the patient on her left side. The fluid contents, a dark greenishyellow color and quite turbid, had a sourish odor. Unfortunately none was preserved for analysis. The quantity was estimated at 2000 c.c. It was not possible to reach the upper end of the sac with the finger inserted in the opening. A probe passed upward, backward and outward for about $25 \mathrm{~cm}$. toward the tail of the pancreas.

The edges of the cyst wall, which were quite thick, were sutured to the abdominal wound and a large rubber drainage-tube inserted into it. The external wound was closed with silkworm gut sutures and an absorbent dressing applied.

The shock of the two operations was quite severe, and the patient's temperature remained subnormal for the first twelve hours. She was very restless and suffered severe pain after the effects of the anesthetic wore off. She was stimulated by morphia and strychnia hypodermically, together with hot saline enemas. The pains continued more or less severe for four days, and the nausea following the anesthesia lasted for threedays.

The discharge from the drainage-tube was very slight after the second day and the tube was removed on the eighth day. The wound was entirely closed on the eighteenth day. The patient gained strength very rapidly as soon as able to take nourishment, and her recovery was uneventful. At the end of six months her health is good and she is able to do her own housework.

\section{SMALLPOX IN OHIO.*}

BY C. O. PROBST, MLD.

SECRETARY OHIO STATE BOARD OF HEALTH. COLUMBUS, OHIO.

Ohio has been having a most interesting epidemic of smallpox during the past year, and I had hoped to he able to present a proper report of it to this meeting. During the past six or eight months, however, I have been kept so busy combatting the disease that I have had no opportunity to complete the report. A few weeks ago I wrote the Chairman that I would be unable to present the paper I had promised, but he informed me that the program had already been printed and that he would expect me to say something on the subject. I have, therefore, very hurriedly prepared a few remarks on some of the more interesting features of our epidemic.

Smallpox made its appearance in Ohio April 6, 1898, and up to June 6, 1899, fourteen months, there have been reported $188^{\circ}$ cases and 30 deaths. Out of 88 counties 45 have been invaded, and the disease has prevailed in 61 cities and villages, besides, in most instances, invading rural districts surrounding them. The disease has been marked by its exceeding mildness and by the many failures to recognize its character, both operating to favor its spread.

* Presented to the Section on State Medicine, at the Fiftieth Annual Meeting of the American Medical Assoclation, held at Columbus, Ohlo, June 6-9, 1899.
The first outbreak occurred in a small village a few miles south of this city and very well illustrates the nature of the disease. A man 72 years old made a visit South, passing through several States where smallpox was prevailing. About a week after returning home he was taken ill and in a few days died with what was called "black measles." Two weeks later his wife, son, and three grandchildren were attacked with what was pronounced "chicken-pox." The children had never been vaccinated, and yet the disease was exceedingly mild, so mild that the children were never bedfast and scarcely missed a meal. The eruption was scanty, rapidly ran its course, and presented much the appearance of chicken-pox. Two or three well-marked cases of smallpox resulted from exposure to these children and settled the diagnosis.

In April, 1898, a' show known as "Uncle Tom's Cabin Show," owned in Columbus, started on its annual tour, which for that year was at first through the western counties of Ohio. Two children, one of them "Topsy," and an adult contracted what physicians called to see the patients pronounced "chicken-pox." The children were not greatly affected at any time, Topsy taking her part in the play each night. 'The adult was quite ill for some time. Six distinct outbreaks in as many different communities were directly traced to this show. A most remarkable feature of these outbreaks is that in none of them was the nature of the disease thus started recognized until months afterward.

One of these communities, where smallpox was thus started, is Wapakoneta. The disease began there in May, and it was not until October that an investigation was made, or called for, and the disease declared "smallpox." The community was largely unvaccinated, most of the children under 12 years of age being unprotected. No restricted measures whatever were employed. Schools and public gatherings continued as usual. The sick were visited and every opportunity was afforded for the spread of the disease. A county fair was held and smallpox patients in the desquamative stage of the disease mingled freely with the visitors. In spite of this great exposure there was comparatively little spread of the disease. In all there were but 203 cases of smallpox in Wapakoneta and vicinity, embracing a population of not less than 9000 people. The great majority of these occurred before preventive measures of any kind were employed.

Perhaps a more remarkable behavior of the disease was shown in Marysville, a village of about 4000 inhabitants. Smallpox appeared there in May, the first three cases having been directly traced to exposure to the troupe referred to above. The disease spread very slowly, attacking children and adults, but only the unvaccinated. The health officer, some time in July or August, became suspicious of smallpox and called a council of physicians. They agreed on a diagnosis of "impetigo contagiosa." No efforts were made to prevent the disease from spreading, the diagnosis of impetigo being accepted, the common people, however, calling it "Spanish measles."

An outbreak of smallpox in Hamilton the 1st of November was directly traced to an importation from Marysville. Inquiry developed the fact, however, that at that time there were no cases of either smallpox or impetigo in Marysville. The disease had actually died out of its own accord.

Two weeks later the health officer of Marysville reported some suspicious cases, and three undoubted cases of smallpox were found in one family. These were quarantined and no others occurred. Probably most of 